\title{
Intracranial Chondrosarcoma: A Rare Case Report
}

Dr. Sarita Nibhoria MD ${ }^{1}$, Dr. Ekta Rani $\mathrm{MD}^{2 *}$, Dr. Aradhana Singh Hada MBBS ${ }^{3}$, Dr. Navjot Kaur, MBBS ${ }^{4}$, Dr. Shilpa Pal, $\mathrm{MBBS}^{5}$

\footnotetext{
${ }^{1}$ Professor, ${ }^{2}$ Assistant Professor, ${ }^{3}$ Junior Resident, ${ }^{4}$ Junior Resident, ${ }^{5}$ Junior Resident, Department of Pathology, GGS Medical College, Faridkot, Punjab, India
}

DOI: $10.36347 /$ simcr.2020.v08i03.039

| Received: 18.03.2020 | Accepted: 25.03.2020 | Published: 27.03.2020

*Corresponding author: Dr. Ekta Rani

\section{Abstract}

Chondrosarcoma is a malignant mesenchymal tumor with cartilageous differentiation. Most chondrosarcoma arise de novo, but some develop in a pre-existing benign cartilaginous lesion. Intracranial, extraosseous chondrosarcoma of the classic type are rare. According to the World Health Organization, chondrosarcomas are divided into three categories based on their histological grade. We are reporting a case of an 18-year-old male presented with complaints of right sided weakness with alleged history of road side accident, given an impression of low grade chondrosarcoma in fronto-parietal region.

Keywords: Chondrosarcoma, mesenchymal tumor, intracranial.

Copyright @ 2020: This is an open-access article distributed under the terms of the Creative Commons Attribution license which permits unrestricted use, distribution, and reproduction in any medium for non-commercial use (NonCommercial, or CC-BY-NC) provided the original author and source are credited.

\section{INTRODUCTION}

Chondrosarcoma is a malignant mesenchymal tumor with cartilageous differentiation. Most chondrosarcoma arise de novo, but some develop in a pre-existing benign cartilaginous lesion. Intracranial, extraosseous chondrosarcoma of the classic type are rare [1]. The same is true for extraskeletal myxoid chondrosarcoma, which has been reported to arise within the brain as well as in the leptomeninges of the brain [2]. Chondroid tumors occur predominantly in the axial skeleton and rarely may have an extraskeletal origin. Intracranial chondroid tumors constitute approximately $<0.16 \%$ of all primary brain neoplasms [3]. It is assumed that chondrosarcomas originate from remnants of embryonal cartilage or from metaplasia of meningeal fibroblasts [4].

\section{Case Report}

We are reporting a case of an $18^{-}$year- old male presented with complaints of right sided weakness with alleged history of road side accident. MRI of the head showed large acute to subacute extra dural haemorrhage along left frontoparietal temporal convexity with mass effect causing effacement of ipsilateral gyral sulcai spaces and left lateral ventricle with dilatation of contralateral right ventricle and midline shift measuring $6.5 \mathrm{~mm}$ towards right side with left uncal herniation. Provisional diagnosis of meningioma was made by the consultant. Left Fronto-tempero-parietal craniotomy was done and with excision of lesion was done. Sample sent in $10 \%$ formalin to pathology department for Histopathological examination. On gross- Received an already cut opened multiple gray- white glistening tumor tissue pieces measuring $8 \mathrm{~cm} \times 4 \mathrm{~cm} \times 3 \mathrm{~cm}$. External and cut surface is light brown with glistening appearance [Figure A]. On microscopy [Figure B, C, D]- sections examined show tumor arranged in the lobules having attached congested benign meningeal tissue and separated by fibrovascular stroma. These tumor oval- to- ${ }^{-}$spindle- ${ }^{-}$shape cells along having round to oval hyperchromatic nuclei and moderate amount of eosinophilic to vacuolated cytoplasm. Few binucleated and multinucleated chondrocytes with plump hyperchromatic nucleus were seen. Impression-the histological features are those of mesenchymal tumor possibly of chondrosarcoma grade I was given. 


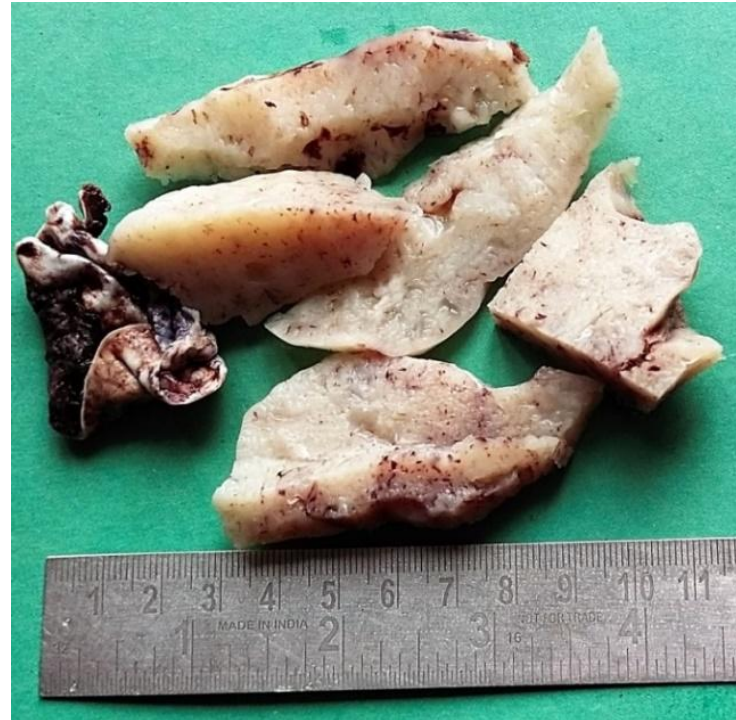

Fig-A: Gross image of specimen received in multiple pieces

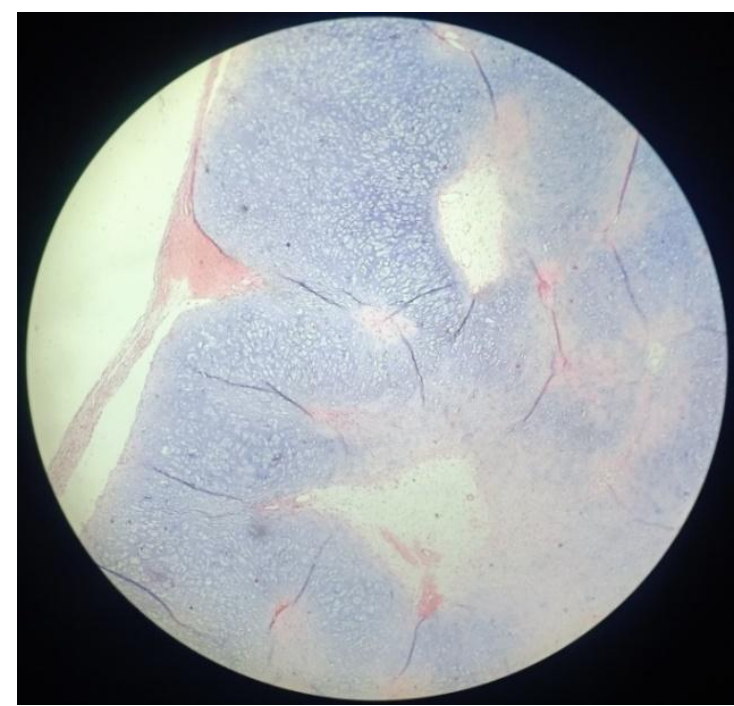

Fig-B: Showing irregularly shaped hypercellular lobules of cartilage $(\mathrm{H}$ and $\mathrm{E}, \times \mathbf{1 0 0})$

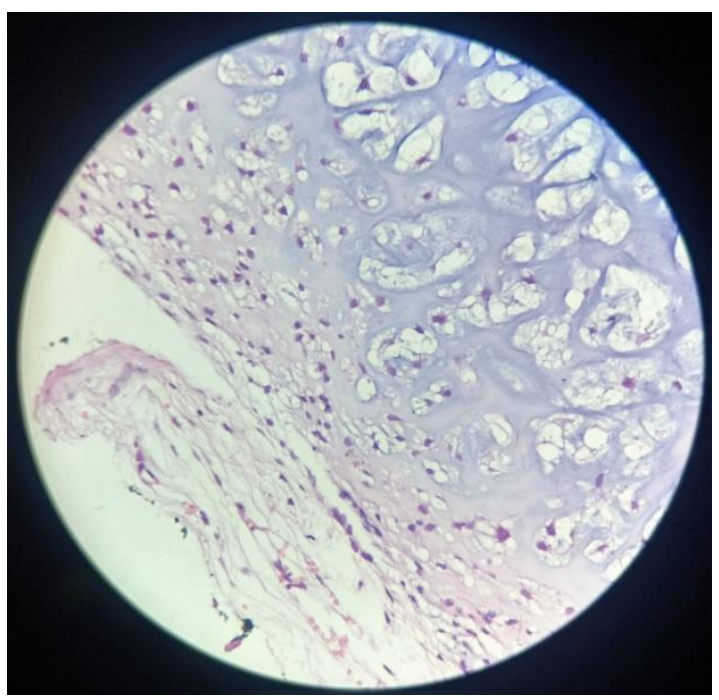

Fig-C: 400X magnification, tissue section showing peripherally attached meninges

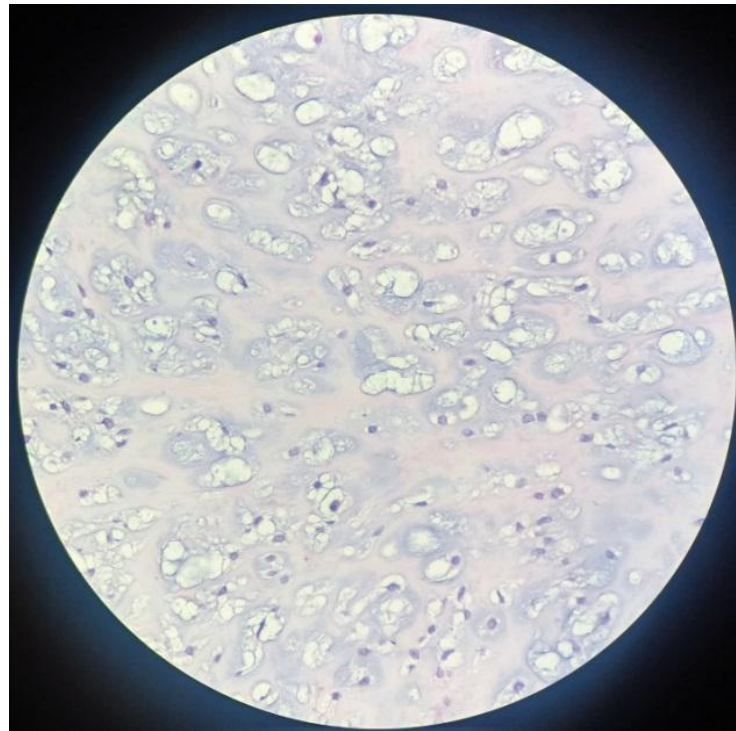

Fig-D: 400X magnification showing chondrocytes arranged in diffuse sheets.

\section{DISCUSSION}

Chondrosarcomas are the third most common primary malignant neoplasms of bone [1]. Chondrosarcoma can occur in wide age groups. Most mesenchymal chondrosarcomas are reported in the second or third decade with a slight female preponderance [5]. Most frequent intracranial location of chondrosarcoma is the skull base $(76.19 \%)$, in the middle cranial fossa, arising from the spheno- occipital synchondrosis. Four subtypes of chondrosarcoma are known: conventional (hyaline or myxoid), dedifferentiated, clear cell, and mesenchymal [6]. According to the World Health Organization, chondrosarcomas are divided into three categories based on their histological grade: grade I: welldifferentiated, grade II: moderately-differentiated, and grade III: poorly-differentiated [7]. Grade I chondrosarcoma might be differentiated from enchondroma with difficulty, featuring slightly higher cellular density and more cellular atypia

Compared to enchondroma [8, 9]. Grade II chondrosarcoma is more cellular compared to grade I, with a lobulated growth pattern. The tumor cells feature enlarged, irregular and hyperchromatic nuclei. Grade III chondrosarcoma is hypercellular with enlarged and hyperchromatic cell nuclei that may become fusiform. The prognosis of chondrosarcomas depends on the histological grade. Mitotic figures and necrosis are commonly seen $[8,9]$. Their exact histogenesis is not known. In a study of review of 55 cases, majority of mesenchymal chondrosarcomas showed an attachment to meninges. Three theories were postulated to explain the presence of cartilage in meninges: first, metaplastic change of meningeal fibroblasts; second, origin from primitive multipotential mesenchymal cells; and third, tumor may arise from embryonal rests of cartilaginous matrix of the skull in the dura [10]. Mesenchymal chondrosarcoma is a rare high- grade tumor with very 
high tendency for local recurrence and distant metastasis.

\section{CONCLUSION}

Most common intracranial location of chondrosarcoma is the skull base but in our case report lesion was found in fronto-parietal region which is rarest of rare. Intracranial mesenchymal chondrosarcoma is very difficult to differentiate by radiologic studies, hence it should also be considered as differential diagnosis in intracranial lesions.

\section{REFERENCES}

1. Chandler JP, Yashar P, Laskin WB, Russell EJ. Intracranial chondrosarcoma: a case report and review of the literature. Journal of neuro-oncology. 2004 May 1;68(1):33-9.

2. Chaskis C, Michotte A, Goossens A, Stadnik T, Koerts G, D'Haens J. Primary intracerebral myxoid chondrosarcoma: Case illustration. Journal of neurosurgery. 2002 Jul 1;97(1):228-.

3. Gitelis ST, Bertoni FR, Picci PI, Campanacci MA. Chondrosarcoma of bone. The experience at the Istituto Ortopedico Rizzoli. The Journal of bone and joint surgery. American volume. 1981 Oct;63(8):1248-57.
4. Kretzschmar HA, Eggert HR. Mesenchymal chondrosarcoma of the craniocervical junction. Clinical neurology and neurosurgery. 1990 Jan 1;92(4):343-7.

5. Chen JY, Hsu SS, Ho JT. Extraskeletal intracranial mesenchymal chondrosarcoma: case report and literature review. The Kaohsiung journal of medical sciences. 2004 May 1;20(5):240-6.

6. Dorfman H: Bone Tumors. St. Louis: Mosby; 1998.

7. Bloch OG, Jian BJ, Yang I, Han SJ, Aranda D, Ahn BJ, Parsa AT. A systematic review of intracranial chondrosarcoma and survival. Journal of Clinical Neuroscience. 2009 Dec 1;16(12):1547-51.

8. Bjornsson J, McLeod RA, Unni KK, Ilstrup DM and Pritchard DJ: Primary chondrosarcoma of long bones and limb girdles. Cancer. 83(10): 2105-2119, 1998.

9. Pritchard DJ, Lunke RJ, Taylor WF, Dahlin DC, Medley BE. Chondrosarcoma: a clinicopathologic and statistical analysis. Cancer. 1980 Jan 1;45(1):149-57.

10. Salvati M, Caroli E, Frati A, Piccirilli M, Agrillo A, Brogna C, Occhiogrosso G, Giangaspero F. Central nervous system mesenchymal chondrosarcoma. Journal of experimental \& clinical cancer research: CR. 2005 Jun;24(2):31724. 